\title{
Cyclic Softening of Low-plasticity Clay and its Effect on Seismic Foundation Performance
}

\author{
Daniel B. Chu ${ }^{1}$, Jonathan P. Stewart ${ }^{2}$, P.S. Lin $^{3}$, and R.W. Boulanger ${ }^{4}$
}

\begin{abstract}
Significant occurrences of ground failure in the form of liquefaction, ground softening, and lateral spreading occurred in Wufeng, Taiwan during the 1999 Chi-Chi earthquake $\left(\mathrm{M}_{\mathrm{w}}=7.6\right)$. The Wufeng region is located adjacent to the ruptured fault on the foot wall, and experienced peak accelerations $\sim 0.7 \mathrm{~g}$. We describe the results of field investigations and analyses of a small region within Wufeng that exhibited a range of ground performance. The investigated region consists of an E-W trending line of $350 \mathrm{~m}$ length. The east end of the line is a residential area with single-story structures for which there was no surface evidence of ground failure. The west end of the line had 3-6 story reinforced concrete structures that were heavily damaged structurally, but which also underwent extensive foundation failures including differential settlement, foundation punching failures, and full foundation bearing failures. No ground failure was observed in the free-field at the west end of the line. Surficial soils consist of low-plasticity silty clays that extended to 8-12 m depth in the damaged area (west side), and 3-5 m depth in the undamaged area (east side). Analyses were performed of the potential for cyclic softening of the clays, which effectively investigates the potential for large cyclic shear strains to develop. The resistance of the clay to cyclic softening is evaluated using the results of material-specific strength testing (both monotonic and cyclic). The seismic demand applied to the soil is evaluated from ground response analyses (to investigate demand from ground shaking) as well as soil-structure interaction analyses (to investigate demand associated with base shears and moments in both six- and one-story structures). Results of the analysis indicate low factors of safety in foundation soils below the six-story building during earthquake shaking, which contributes to bearing capacity failures at the edges of the foundation due to rocking effects. Similar analyses indicate high factors of safety (above unity) in foundation soils below one-story buildings as well in the free field. Accordingly, analysis of the site within a framework that systematically accounts for the clayey nature of the foundation soils successfully predicted the field performance.
\end{abstract}

Keywords: Earthquake, Cyclic softening, Low-plasticity clay, Cyclic stress ratio, Cyclic resistance ratio, Bear capacity.

\section{INTRODUCTION}

The 1999, Chi-Chi, Taiwan Earthquake caused extensive ground failure and structural damage in Wufeng, Taiwan. Liquefaction-induced ground failure occurred in the form of sand boils, lateral spreading, and ground settlement (Stewart, 2001). However, some of the most interesting examples of ground failure occurred in areas underlain by low plasticity clayey soils, in which ground failure was

\footnotetext{
${ }^{1}$ Chief Geotechnical Engineer, Ninyo \& Moore, Irvine CA. USA. (Daniel.chu@ninyoandmoore.com)

2 Associate Professor and Vice Chair, University of California, Civil \& Environ. Engineering Dept., Los Angeles, CA USA

${ }^{3}$ Professor, National Chung-Hsing University, Taichung, Taiwan

${ }^{4}$ Professor, University of California, Civil \& Environmental Engineering Department, Davis, CA USA
} 
generally not manifest in the free-field or beneath low-rise buildings, but only beneath relatively tall 4- to 6-story reinforced concrete frame structures with shallow foundations (mats and footings). As will be shown in this paper, these case histories push the limits of liquefaction analysis tools that form the current standard of practice. Accordingly, in this paper we analyze a well-documented case history using an alternative framework for ground failure in clayey soils.

\section{CASE HISTORY- WUFENG SITE A}

The subject of this paper is a location referred to as Site A located in the southern part of Wufeng. It consists of a series of buildings along an E-W trending line $350 \mathrm{~m}$ in length (Fig. 1). The east end of the line is a residential area with single-story buildings, which sustained neither structural damage nor ground failure (see Fig. 2). This single-story housing community is located approximately 200 meters from the fault rupture. The west end of the line consisted of 3-6 story reinforced concrete buildings that sustained not only heavy structural damage, but also underwent extensive foundation failures including differential settlement, foundation punching failures, and foundation bearing failures (see Fig. 3). These two residential communities (the single-story housing in the east side and multi-story apartments in the west side) are separated by a 30-meter-wide street. In the west side, 11 out of 18 mid-rise buildings sustained severe damage and were demolished within 3 months of the earthquake. In addition, a 2- to 3-story building complex used as a day care facility also collapsed and was demolished. Typical building damage involved column failure in the soft first floor level. These buildings also sustained settlement on the order of 10 to $30 \mathrm{~cm}$. Many buildings also showed column footing punching failures with intermediate slab heaving. We surveyed the remaining slab of two buildings on site and found the differential heave at the center of the slab ranging from $0.22 \mathrm{~m}$ over $2.7 \mathrm{~m}$ ( $8 \%$ heave) to $0.37 \mathrm{~m}$ over $6 \mathrm{~m}(6 \%$ heave $)$.

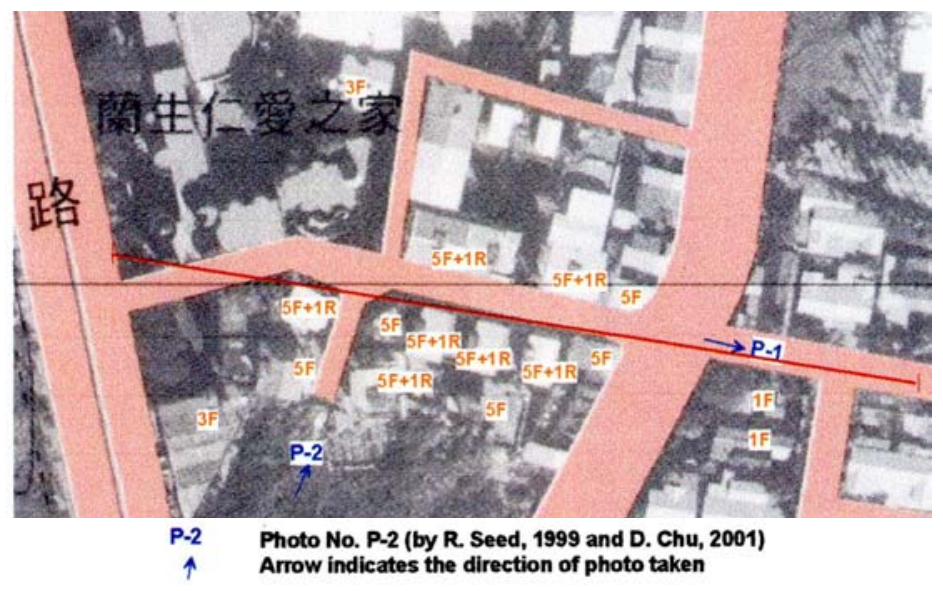

Figure 1. Basemap for Wufeng Site A. The aero photo used to construct the base map was taken in 1997. Building height is indicated along with photo locations. $(5 \mathrm{~F}+1 \mathrm{R}$ indicates 5 -story plus roof addition).

\section{FIELD EXPLORATION}

In order to evaluate the subsurface soil conditions at Wufeng Site A, an exploratory program was performed in 2001 and 2002 that consisted of four rotary wash borings with SPT and in-situ vane shear tests, four back-hoe test pits for in-situ vane shear tests and nine CPT soundings. Fig. 4 presents an east-west trending geotechnical soil profile through the site. Based on the field investigation and results of laboratory testing, the east side of Site A is underlain by an approximately 3- to 10-m thick low plasticity silt and clay layer (plasticity index [PI] ranging from 0 to 13) and the west side is underlain by an approximately 8- to 12-m thick low plasticity (PI ranging from 1 to 16 ) silt and clay layer. The surficial silty clays have characteristics that are at the boundaries of what is often judged liquefiable versus nonliquefiable by index-test-based criteria such as that proposed by Bray et al were susceptible to liquefaction, while soils with $12<\mathrm{PI}<20$ and $\mathrm{w}_{\mathrm{n}}>80 \% \mathrm{LL}$ were "systematically more 


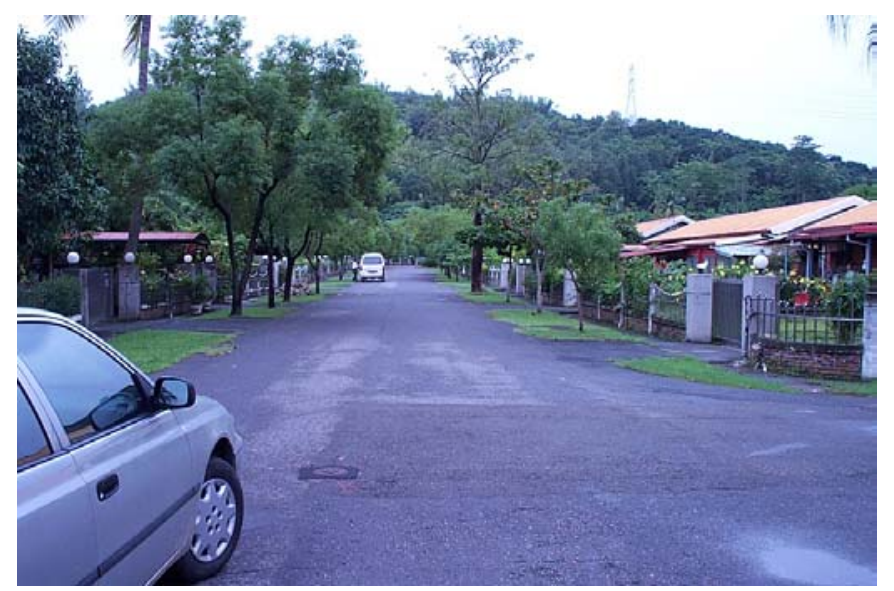

Figure 2. Photo P-1 showed the single-story residential building in the east side of Wufeng Site A (by D. Chu, 2001)

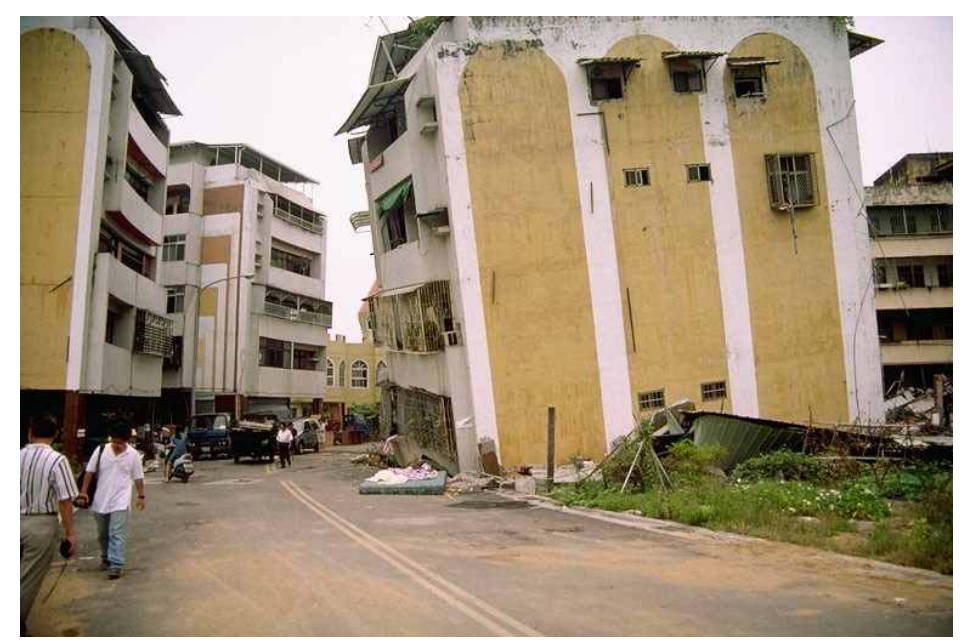

Figure 3. Photo P-2 showed the collapsed 6-story reinforced concrete building in Wufeng Site A (by R. Seed, 1999)

resistant to liquefaction but still susceptible to cyclic mobility". Figure 5 indicates the LL, PI and (2004). Bray et al. concluded that soils with $\mathrm{PI} \leq 12$ and water contents $\left(\mathrm{w}_{\mathrm{n}}\right)$ greater than $85 \%$ of the liquid limit (LL) $\mathrm{w}_{\mathrm{n}}$ test results for upper silty clays in Wufeng Site A and the plots from Bray et al.'s liquefaction susceptibility criteria. As can be seen in Figure 5, approximately $50 \%$ of the clays will be susceptible to liquefaction according to Bray et al.'s criteria. However, as described in detail by Chu (2006), a liquefaction-based framework is unable to explain the observed field performance.

\section{LABORATORY TESTING}

A suite of soil tests including soil index tests, consolidation, isotropically consolidated undrained (ICU) monotonic triaxial compressions tests, cyclic undrained triaxial tests, and post-cyclic monotonic triaxial compression tests was carried out in the soil dynamic testing lab at the Civil Engineering Department of National Chung-Hsing University in Taiwan. Details of each laboratory test procedure and the results are described and presented by Chu (2006). Summaries of the soil shear strength and stress profiles at the west side (3-6 story buildings) of the site are presented in Fig. 6. Undrained strength ratios were evaluated using the SHANSEP technique (Ladd, 1991) using triaxial testing, with the results shown in Figure 7. Those results were used to estimate pre-earthquake shear strengths beneath the affected structures, with the results in Figure 6. Also shown in Figure 6 are undrained shear strengths $\left(s_{u}\right)$ from in-situ vane shear tests and calibrated CPT correlations [using 
$\left.N_{k}=\left(q_{c}-\sigma_{\mathrm{v}}\right) / s_{u}=20\right]$. The in-situ vane shear tests were used to evaluate both peak and residual shear strengths, and indicated an average sensitivity of approximately 2.1 .

Cyclic triaxial testing was performed on selected specimens to evaluate the number of cycles of shaking required to achieve $\pm 3 \%$ axial strain. The resulting $\left(\tau_{c y d} / s_{u}\right)-N$ relationships are shown in Fig. 8. Following the cyclic testing, post-cyclic undrained shear strengths were evaluated by monotonically shearing the specimens to failure. The post cyclic shear strengths were considerably less than the precyclic strengths, as shown in Figure 7. The degradation ratio (ratio of pre-cyclic strength ratio divided by the post-cyclic strength ratio) is approximately 1.5 and 2.2 for over consolidation ratios (OCRs) of 2 and 3, respectively. The degradation ratio is generally slightly less than the sensitivity (2.1).

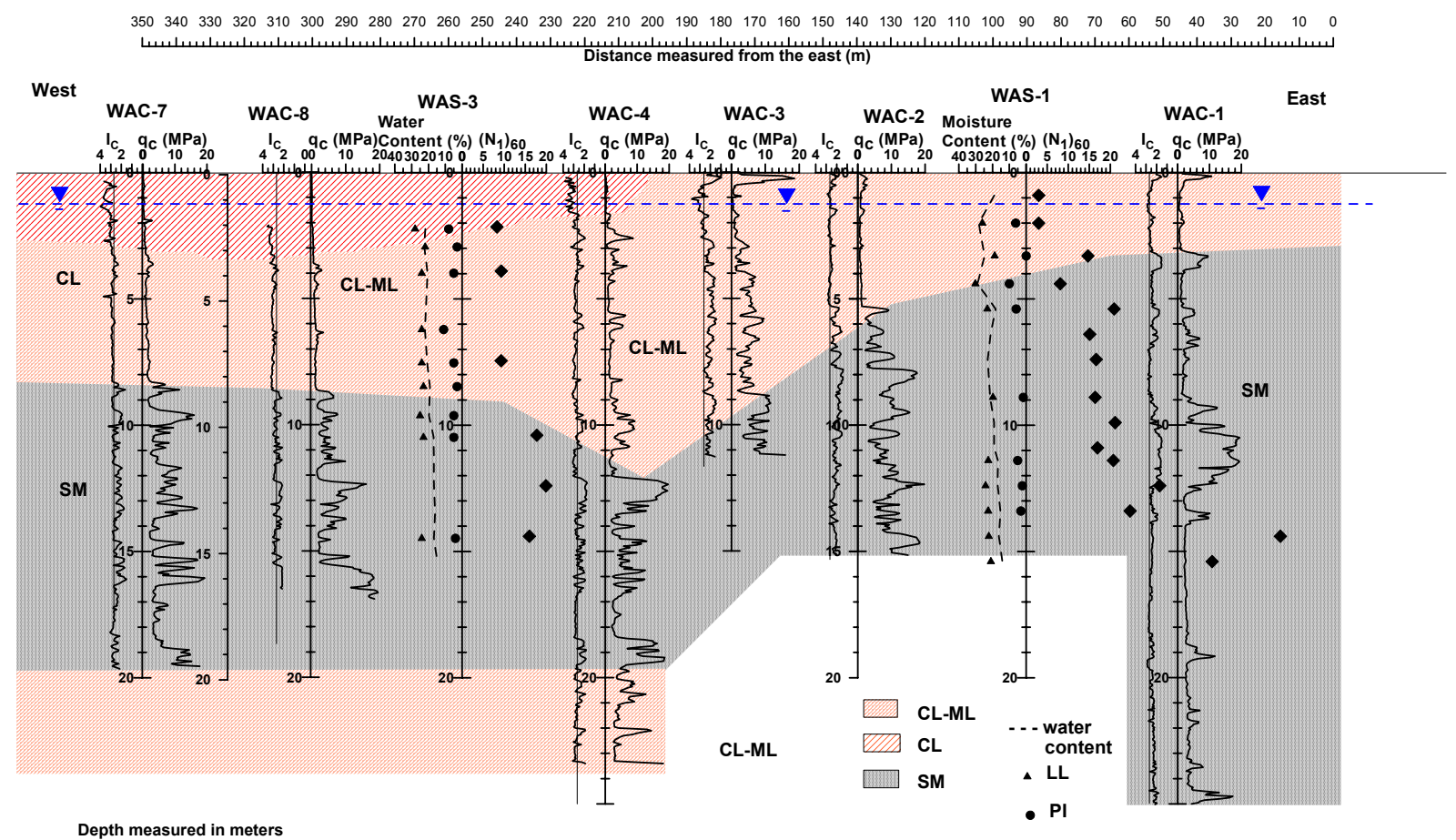

Figure 4. Geotechnical cross section along the east-west direction of Wufeng Site A

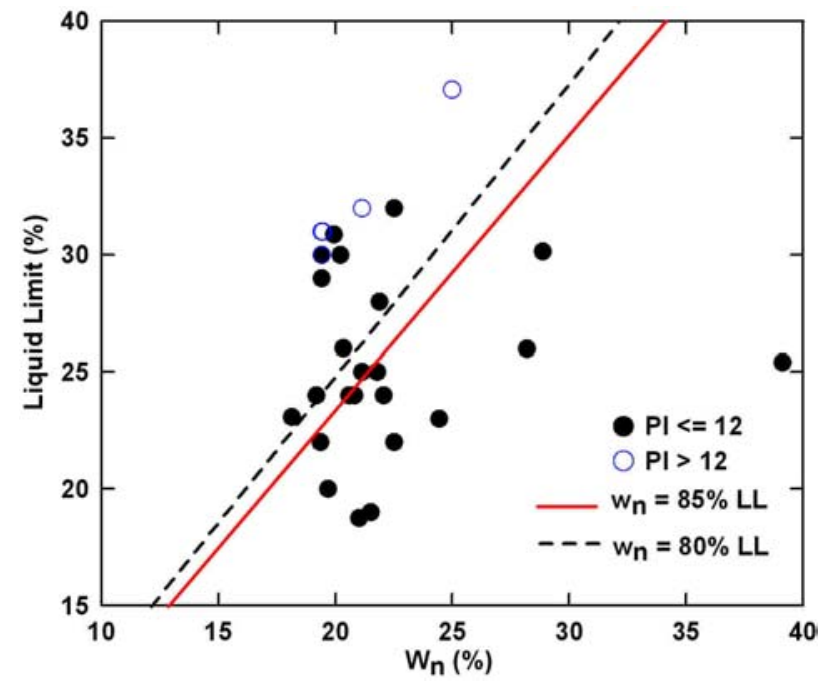

Figure 5. Soil index test results (LL, PI and $\mathrm{w}_{\mathrm{n}}$ ) of the silty clays in Wufeng Site A and the liquefaction susceptibility criteria (Bray et al. 2004) 

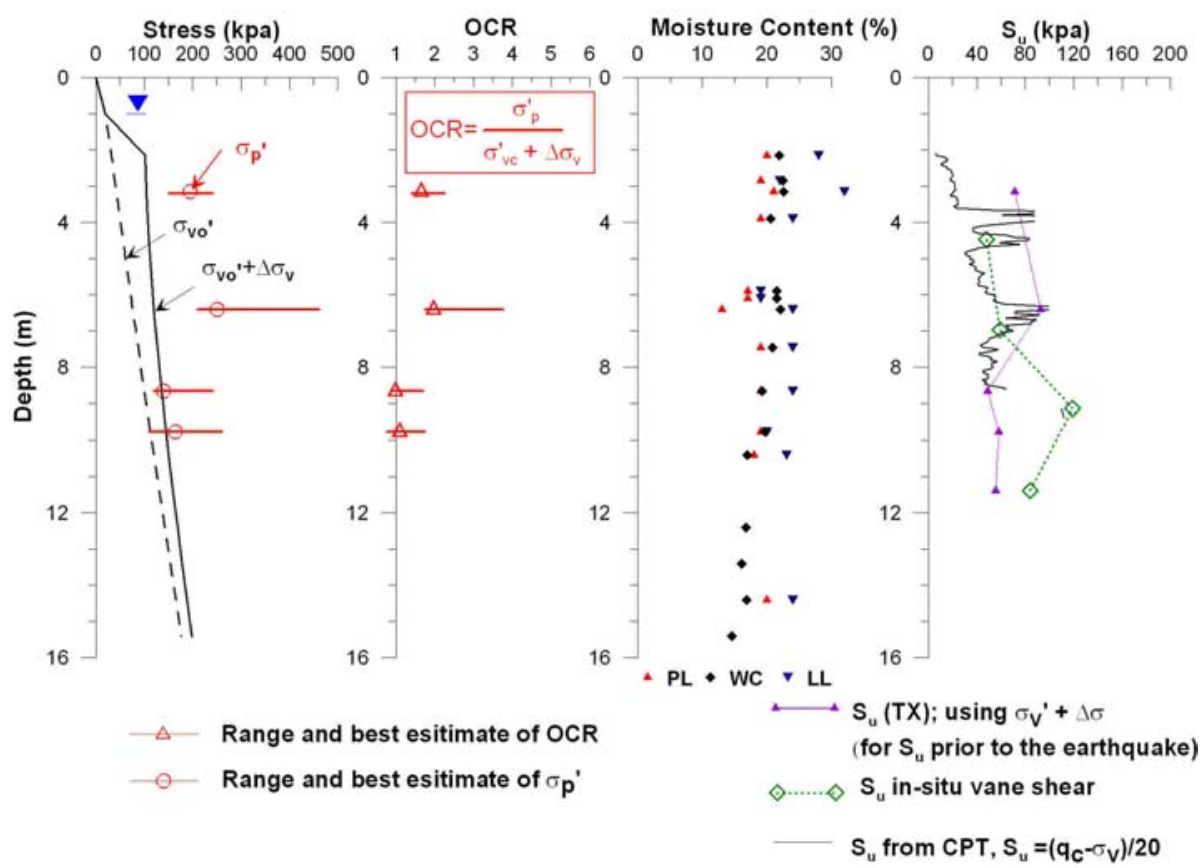

Figure 6. Soil index tests, consolidation history and undrained shear strength profile for the west side

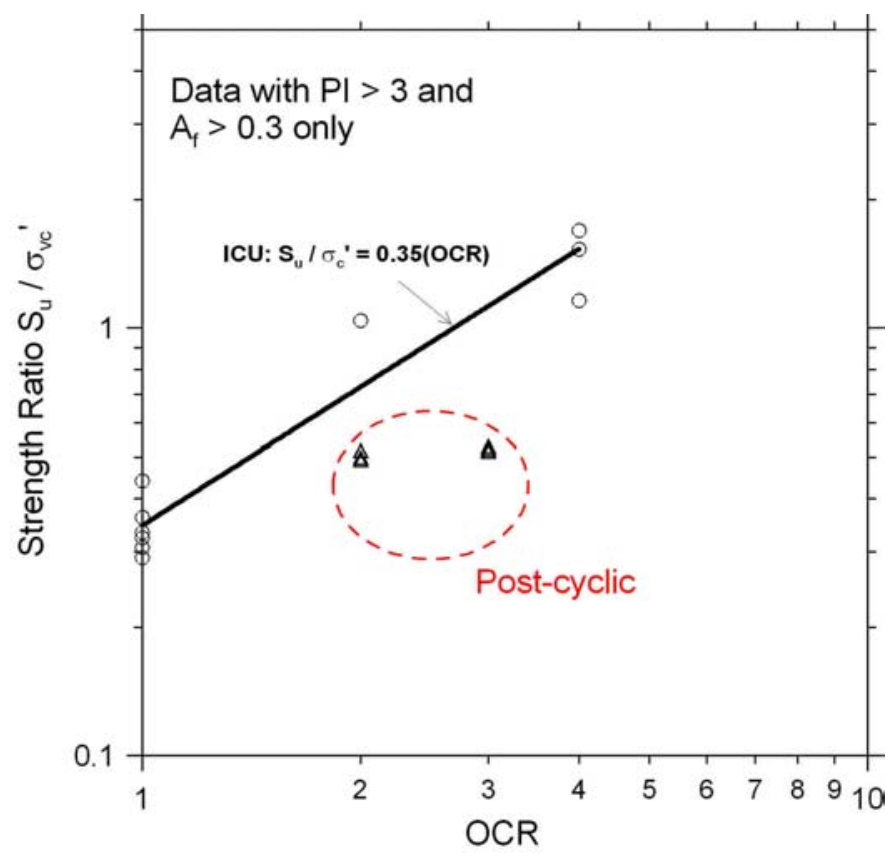

Figure 7. Comparison of the undrained shear strength ratio between the pre-cyclic monotonic and post-cyclic monotonic tests 


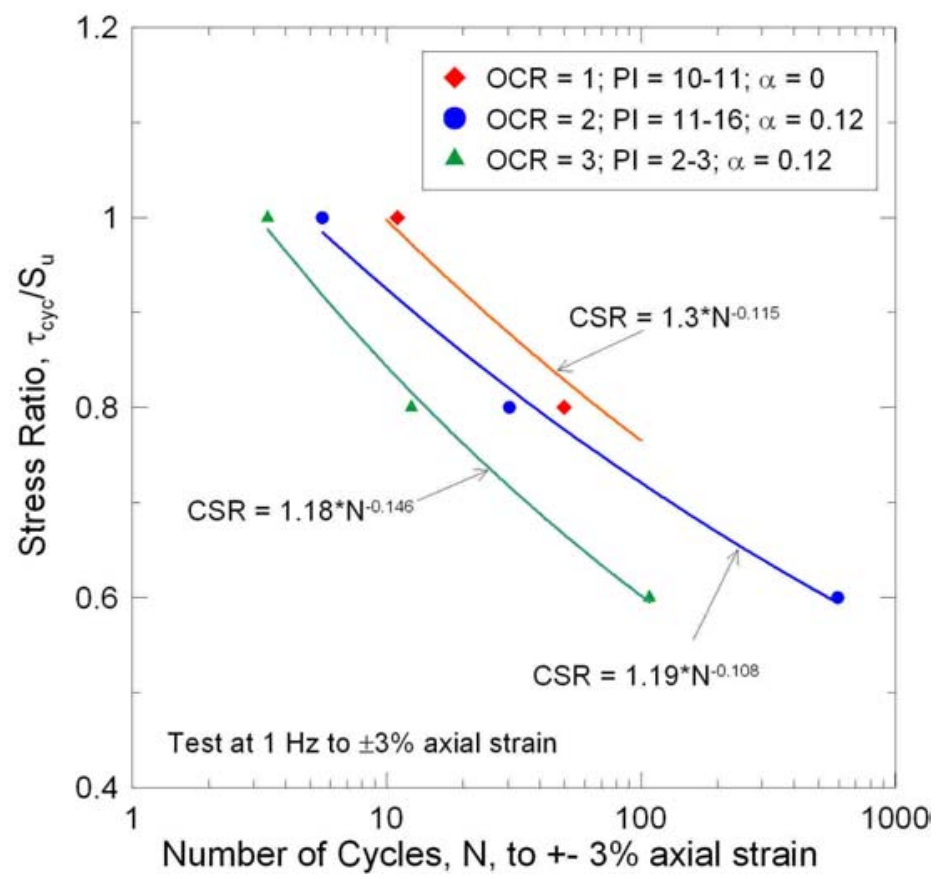

Figure 8. Stress ratio $\left(\tau_{c y c} / S_{u}\right)$ versus $N$ curves resulting from cyclic triaxial undrained tests

\section{ANALYSIS OF CYCLIC SOFTENING OF CLAYS}

The potential for cyclic softening of the on-site low-plasticity clay during earthquake shaking was analyzed by comparing the seismic demand in the form of a Cyclic Stress Ratio (CSR) and the cyclic resistance in the form of Cyclic Resistance Ratio $(C R R)$. These comparisons provide insight into the potential for the clays to have experienced large cyclic strains during earthquake shaking, and are conducted using the general procedure described by Boulanger and Idriss (2004).

\section{Seismic Demand}

The CSR representing the seismic demand is evaluated in the traditional manner for soil liquefaction (i.e., the ratio of a representative cyclic shear stress acting on a horizontal plane to the pre-earthquake vertical effective stress. It is necessary to consider the demand placed on the soil both from the free-field site response and from soil-structure interaction effects associated with the vibrating structure. Free-field seismic demand is evaluated using (1) simplified procedures, and (2) equivalent-linear and nonlinear ground response analyses. In the simplified procedure, CSR is calculated as (Seed and Idriss, 1971):

$$
C S R=0.65 \frac{(P H A / g) \sigma_{v c}}{\sigma_{v c}^{\prime}} r_{d}
$$

where PHA represents the peak horizontal acceleration at the ground surface, $g$ is the acceleration of gravity, $\sigma_{v c}$ and $\sigma_{v c}^{\prime}$ represents the total and effective vertical effective consolidation stresses at the depth of interest, and $r_{d}$ is a stress reduction factor. Chu (2006) utilized stress reduction $\left(r_{d}\right)$ factors from Cetin et al. (2004) and Idriss and Boulanger (2006), although in this paper we emphasize the results of site-specific wave propagation analyses. Seismic demand is induced in the foundation soils by the inertial forces associated with the vibrating building both because of the base shear at the foundation-soil interface and rocking, which cycles the normal stresses at the ends of the foundation. Details of the site response and soil-structure interaction analysis are presented by Chu (2006). 


\section{Evaluation of Seismic Resistance}

The $C R R$ represents the ratio of cyclic shear resistance to initial vertical effective stress. $C R R$ can be expressed as:

$$
C R R=\left(\frac{\tau_{c y c}}{\sigma_{v c}^{\prime}}\right)=C_{2 D} \times\left(\frac{\tau_{c y c}}{s_{u}}\right)_{N, \alpha} \times \frac{s_{u}}{\sigma_{v c}^{\prime}}
$$

where $\left(\tau_{c y c} / s_{u}\right)_{N, \alpha}$ represents the stress ratio evaluated for an appropriate value of $N$ (number of cycles) and $\alpha$ (ratio of static shear stress ratio on a horizontal plane to $\sigma_{v c}^{\prime}$ ). The shear stress ratio $\left(\tau_{c y c} / s_{u}\right)_{N, \alpha}$ and the shear strength ratio $\left(s_{u} / \sigma_{v c}^{\prime}\right)$ are evaluated from laboratory test results (i.e., Figures 7 and 8). $C_{2 D}$ accounts for the additional cycles associated with multi-directional shaking relative to single-direction shaking. Details of the analysis are presented by $\mathrm{Chu}$ (2006).

\section{Summary of Findings}

Figure 9 presents $C R R$ and $C S R$ profiles for the surficial clayey materials on the west side of Wufeng Site A. In Fig. 9, CSR profiles at three locations under the mat foundation are shown. The presence of the building affects the seismic demand (CSR) by:

1) increasing $\sigma_{v c}^{\prime}$ for a given depth, which reduce $C S R$, and

2) increasing the cyclic shear stress acting on horizontal/vertical planes $\left(\tau_{\text {hv }}\right)$ due to base shear and rocking, which increase CSR. These effects are accounted for in the CSR profiles shown in Figure 9.

The presence of the building affects the cyclic resistance $(C R R)$ relative to free-field conditions by:

1) increasing the pre-earthquake $\sigma_{v c}^{\prime}$ for a given depth. This reduces OCR, which, in turn, reduces shear strength ratio $\left(s_{u} / \sigma_{v c}^{\prime}\right)$. Per Equation 2, this causes $C R R$ to decrease; and

2) increasing the static shear stress ratio, $\alpha\left(\alpha=\tau_{\text {static }} / \sigma_{v c}^{\prime}\right)$, which decreases stress ratio $\tau_{\text {cyc }} / s_{\mathrm{u}}$. Per Equation 2, this causes $C R R$ to decrease.

Hence, the presence of buildings can cause CSR to increase or decrease, but will tend to cause $C R R$ to decrease. This is illustrated in Figure 9, where CRR decrease is relatively small and the CSR change depends on location. Beneath the center of the foundation (point A), CSR is decreased. Beneath the corner (point C) and edge (point B), CSR is increased near the surface (upper 2 to $5 \mathrm{~m}$ ), and is generally decreased at large depth.

The results indicate that the foundation soils underlying the 6-story structures would be expected to undergo cyclic failure (since $C R R<C S R$ ) from $0-3 \mathrm{~m}$ and $8-10 \mathrm{~m}$ depth. This result is generally consistent with the ground failure observed around these tall buildings. In the free-field, $C R R$ is equal to or slightly greater than CSR from 0 to $3 \mathrm{~m}$ depth when the CSRs from non-linear analyses are used (lower CSRs are predicted by fully nonlinear models, which are considered more realistic; Chu, 2006). This result is generally consistent with the lack of free-field ground failure. Although not shown here for brevity, Chu (2006) shows that on the east side, CRR > CSR over the full depth of the clay (0 to approximately $5.0 \mathrm{~m}$ ) both beneath the one-story structures and in the free-field. This is consistent with field observations of no ground failure in this area.

\section{Bearing Capacity Failure Potential Evaluation}

In this section, we evaluate the bearing capacity of the foundation soils in the west side of Site A to investigate whether established bearing capacity theory, when used with properly chosen undrained 
strength parameters, can successfully predict the observed performance. There are three conditions to be analyzed. Two involve static bearing capacity, one pre-earthquake and one post-earthquake with shear strengths reduced by cyclically induced pore pressures. The third condition involves bearing capacity during strong earthquake shaking.

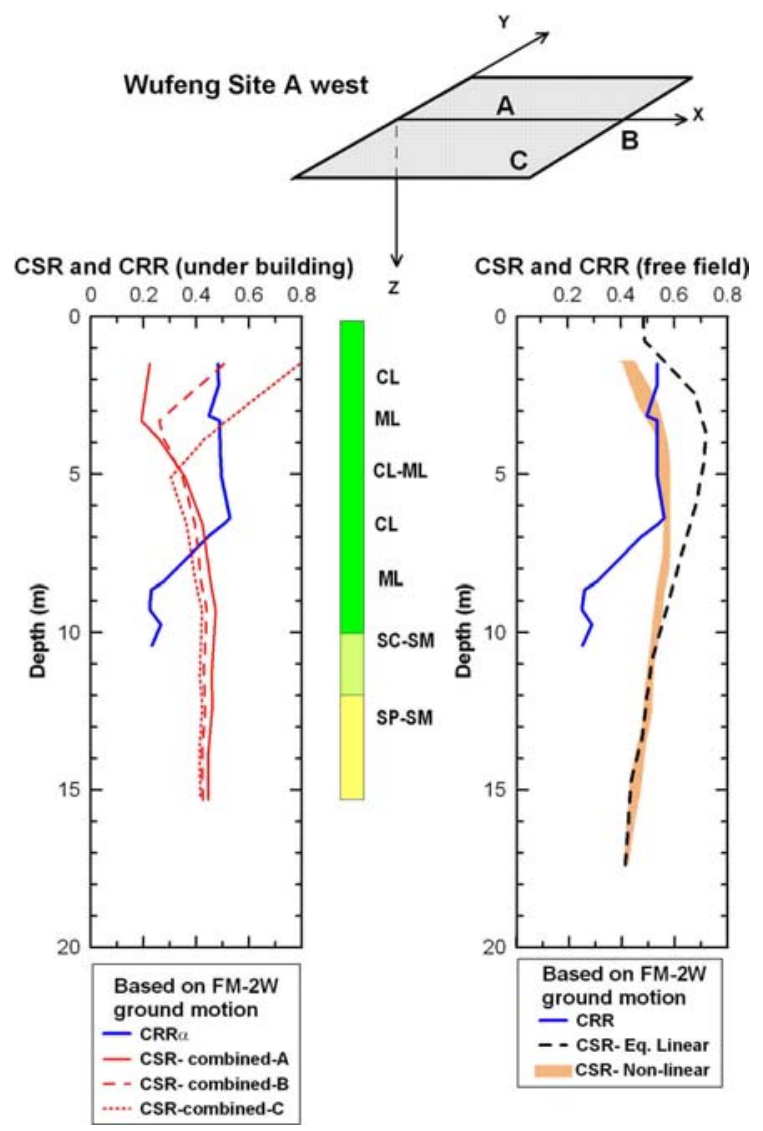

Figure 9. CRR and CSR profiles for the west sides of Wufeng Site A

The long-term, static loading on the foundation is estimated to be $72 \mathrm{kPa}$ (Chu, 2006). Based on the ICU triaxial compression test results as indicated in Figure 7, the averaged undrained shear strength $\left(s_{u}\right)$ of the upper $10 \mathrm{~m}$ clay is approximately $68 \mathrm{kPa}$. Considering the effects of anisotropy, the averaged undrained shear strength $\left(\mathrm{s}_{u \text {-ave }}\right)$ can be taken as $80 \%$ of the triaxial compression $s_{u}$ (Ladd, 1991), which is about $55 \mathrm{kPa}$. Using Vesic (1973) bearing capacity theory, the ultimate bearing capacity for the mat foundation is $350 \mathrm{kPa}$. That yields a factor of safety $\left(\mathrm{FS}_{\text {pre-eqk }}\right)$ of 4.9 against bearing capacity failure prior to the earthquake. Following the earthquake, all conditions remain the same except that the undrained shear strength is reduced by a factor of ranging from 1.5 to 2.2; the post-earthquake factor of safety $\left(\mathrm{FS}_{\text {post-eqk }}\right)$ is then estimated to be 2.2 to 3.3. These analyses indicate that no bearing capacity problems would be expected at the site either prior to or following the earthquake. This is consistent with reports of local residents, which indicate no continuation of foundation settlement following the earthquake.

During the earthquake, the bearing capacity factor $N_{c}$ is modified to $N_{c e}$ to account for inertial forces in the soil mass (sometimes referred to as a kinematic interaction effect on the bearing capacity). Pecker et al. (1996) and Mylonakis et al. (2002) have found that this effect is small for bearing capacity of undrained clays, and for an effective acceleration of approximately $0.4 \mathrm{~g}$ (taken as $2 / 3$ of the peak acceleration), $N_{c e} / N_{c}$ is approximately 0.88 . The analysis of bearing capacity must also account for the "inclination" of the load acting on the footing. Using a peak base shear of $8300 \mathrm{kN}$, giving a V/mg 
ratio of $0.47, F_{c i}=0.85$ using the load inclination factors of Vesic (1973). The vertical stress acting during the earthquake is increased due to foundation rocking to $p_{M}=390 \mathrm{kPa}$. If ( $\mathrm{s}_{\mathrm{u} \text {-ave }}$ ) is taken as the pre-earthquake long-term static value but increased by $40 \%$ to account for the faster earthquake loading rate, the ultimate bearing capacity becomes $366 \mathrm{kPa}$ and the factor of safety during earthquakes $\left(\mathrm{FS}_{\mathrm{eqk}}\right)$ becomes 0.9 . This low $\mathrm{FS}_{\mathrm{eqk}}$ is likely to trigger bearing capacity failure and the associated loss of soil shear strength. If $\left(\mathrm{s}_{\mathrm{u} \text {-ave }}\right.$ ) is then reduced by factors ranging from 1.5 to 2.2 based on the data in Figure 7, then the $\mathrm{FS}_{\text {eqk }}$ is further reduced to values ranging from approximately 0.4 to 0.6. This suggests that the observed foundation failures were in fact bearing failures that occurred due to both earthquake-induced strength reductions from pore pressure generation and large transient moment demands on the foundation.

\section{SUMMARY AND CONCLUSIONS}

The potential for cyclic softening was evaluated for three locations: (1) beneath the foundations of a six story building (where ground failure was observed); (2) beneath the foundation of a single-story building (no observed failure); and (3) in the free-field (no observed failure). Cyclic softening potential is evaluated by comparing the CSR and $C R R$. If $C R R>C S R$ at a given depth, cyclic softening is not expected, whereas cyclic softening is expected if $C R R<C S R$. Beneath the 6-story building, CSR $>C R R$ over two depth intervals $(0-3 \mathrm{~m}$ and $8-10 \mathrm{~m})$, indicating a potential for cyclic softening. Bearing capacity analyses using reduced strengths to account for cyclic softening indicate factors of safety against bearing capacity failure that are less than unity, which is consistent with the field performance.

Factors of safety (FS) for the buildings on the west side are somewhat different for the cyclic softening versus bearing capacity analyses. There are several possible reasons for this, including: 1) Cyclic softening is based on shear stresses imposed on horizontal/vertical planes, whereas bearing capacity is based on vertical loads at the ground surface. The latter will induce failure in the most critical planes (not necessarily horizontal/vertical planes), which would be expected to produce lower FS; 2) The FS analysis for bearing capacity was based on peak cyclic stresses, whereas the cyclic softening analysis was based on "effective" cyclic stresses (i.e., $65 \%$ of the peak cyclic stresses). Given that the bearing capacity analysis is likely more intuitive for practicing engineers, its use for design purpose is likely more desirable.

Analysis of the site in a liquefaction framework is not required to explain the field performance. In fact, $\mathrm{Chu}$ (2006) has shown that such analyses failed to simultaneously explain the failures of the tall structures on the west side and the lack of failure in the free field and in the shorter buildings on the east side. Instead, analysis of the site according to a framework that accounts for the clayey nature of the foundation soils (i.e., Boulanger and Idriss, 2004) is required to explain the observed field performance.

\section{ACKNOWLEDGMENTS}

This project was sponsored by the Pacific Earthquake Engineering Research Center's Program of Applied Earthquake Engineering Research of Lifeline Systems supported by the State Energy Resources Conservation and Development Commission and the Pacific Gas and Electric Company. This work made use of Earthquake Engineering Research Centers Shared Facilities supported by the National Science Foundation under Award \#EEC-9701568. In addition, the support of the California Department of Transportation's PEARL program is acknowledged. 


\section{REFERENCES}

Boulanger, R.W. and Idriss, I.M. (2004). "Evaluating the potential for liquefaction or cyclic failure of silts and clays," Report No. UCD/CGM-04/01, Department of Civil \& Environmental Engineering, College of Engineering, University of California at Davis.

Bray, J.D., Sancio, R.B., Riemer, M.F., and Durgunoglu, H.T., (2004). "Liquefaction susceptibility of fine-grained soils," $11^{\text {th }}$ Int. Conf. On Soil Dynamic and Earthquake Engineering and 3rdInt. Conf. On Earthquake Geotechnical Engineering, Berkeley, California.

Cetin, K.O., Seed, R.B., Kiureghian, A.D., Tokimatsu, K., Harder, L.F. Jr., Kayen, R.E., and Moss, R.E.S. (2004). "Standard penetration test-based probabilistic and deterministic assessment of seismic soil liquefaction potential," Journal of Geotechnical and Geoenvironmental Engineering, ASCE, 130 (12), 1314-1340.

Chu, D.B. (2006). "Case studies of soil liquefaction of sands and cyclic softening of clays induced by the 1999 Taiwan Chi-Chi earthquake," Ph.D. Dissertation, Department of Civil and Environmental Engineering, University of California, Los Angeles.

Idriss, I. M., and Boulanger, R. W. (2006). "Semi-empirical procedures for evaluating liquefaction potential during earthquakes." Journal of Soil Dynamics and Earthquake Engineering, Elsevier, $26,115-130$.

Ladd, C. C. (1991). "Stability evaluation during staged construction," J. Geotech. Engrg., ASCE, 117 (4), 540-615.

Mylonakis, G., Gazetas, G, Nikolaou, S. and Chauncey, A. (2002). Development of Analysis and Design Procedures for Spread Footings, City University of New York, Department of Civil Engineering, New York, New York, and University at Buffalo, State University of New York, Department of Civil, Structural and Environmental Engineering, Buffalo, New York, Technical Report MCEER-02-0003.

Pecker, A., Auvinet, G., Salencon, J., Romo, M.P., and Verzura, L. (1996)."Seismic bearing capacity of shallow foundations on soft soils," Contract CI1-CT92-0069, Final Report, Geodynamic et Structure.

Stewart, J.P.: coordinator (2001). Chapter 4: Soil liquefaction. Chi-Chi, Taiwan Earthquake of September 21, 1999 Reconnaissance Report, J. Uzarski and C. Arnold, eds., Earthquake Spectra, Supplement A to Vol. $17,37-60$.

Vesic, A.S. (1973). "Analysis of ultimate loads of shallow foundations," J. Soil Mech. \& Foundations Div., ASCE, 99(1), 45-73. 